\title{
ENSINAR E APRENDER EM TEMPOS PANDÊMICOS: (RE)INVENTANDO PRÁTICAS PEDAGÓGICAS
}

\begin{abstract}
Reviu Barros ${ }^{1}$
RESUMO: Este artigo apresenta um breve recorte a partir de uma reflexão empírica nas práticas pedagógicas de professores em tempos pandêmicos. A intencionalidade é abordar de forma qualitativa, três aspectos importantes para a aprendizagem, tais como: o uso das tecnologias digitais nos processos de ensino-aprendizagem, a ação docente e o ato reflexivo sobre as estratégias de ensino. Nesse tripé de intenções, procura-se com o suporte teóricos de autores que abordam o tema, enriquecer as estratégias de ensino aprendizagem com os recursos digitais e sua extrema importância para o ensino em tempos de pandemia. Desse modo, dar continuidade no processo de formar os alunos para apropriação crítica e criativa das tecnologias disponíveis; e apresentar técnicas que podem ajudar ao docente a (re)inventar critérios objetivos e subjetivos para a atribuição de estratégias para a aprendizagem significativa dos alunos.
\end{abstract}

Palavras-Chave: Práticas Pedagógicas. Tecnologias. Aprendizagem. Pandemia.

ABSTRACT: This article presents a brief excerpt from an empirical reflection on the pedagogical practices of teachers in pandemic times. The intention is to address three important aspects for learning, such as: the use of digital technologies in the teaching-learning processes, the teaching action, and the reflective act on the teaching strategies. In this tripod of intentions, with the theoretical support of authors who approach the theme, we seek to enrich teaching and learning strategies with digital resources and their extreme importance for teaching in times of pandemic. Thus, to continue the process of training students for critical and creative appropriation of available technologies; and to present techniques that can help the teacher to ( $r e$ ) invent objective and subjective criteria for the attribution of strategies for the students' meaningful learning.

Keywords: Pedagogical Practices. Technologies. Learning. Pandemic.

\section{INTRODUÇÃO}

\footnotetext{
${ }^{1}$ Reviu Barros, é professor universitário, graduado em Letras e Pedagogia, Especialista e Mestre em Educação. Universidade: UNINTER - Curitiba - Paraná. Lattes: http://lattes.cnpq.br/868565119248258o.E-mail: reviub@yahoo.com.br_https://orcid.org/oooo-ooor$8322-316 \mathrm{X}$
} 
Este artigo tem por objetivo elaborar uma reflexão, em uma abordagem qualitativa, sobre as práticas pedagógicas de professores em acordo com o cenário atual na educação, e o uso das ferramentas tecnológicas no desafio para ensinar e aprender em tempos pandêmicos. É, necessário saber que, educação inclui o ato reflexivo contínuo sobre estratégias de ensino que podem se tornar mais eficazes na aprendizagem dos alunos.

Diante a maior pandemia do século XXI que está sendo causada pela proliferação do coronavírus o COVID-ı, no Brasil e no mundo, tem afetado a todos, nos diferentes aspectos da sociedade e impulsionado mudanças emergenciais, inclusive na área da educação. Estamos imersos em um mundo de incertezas, onde quase todos os profissionais, inclusive os professores, de setores comerciais, da indústria tiveram que se adaptar para evitar o contágio com o vírus.

Quando foi decretado o fechamento das escolas em março de 2020, as primeiras pessoas infetadas com a COVID-ı9, a 2 de março e face à evolução do contágio, a 16 de março (próximo do final do $2^{\circ}$ período letivo), a decisão do governo foi encerrar as atividades nas escolas dos níveis de ensino pré-escolar, básico e secundário, e, gradualmente, as instituições de ensino superior foram seguindo o mesmo propósito.

Segundo Grandisoli (2020), cerca de 48 milhões de estudantes deixaram de frequentar as atividades presenciais nas mais de 180 mil escolas de ensino básico espalhadas pelo Brasil como forma de prevenção à propagação do coronavírus, dados de acordo com o último censo escolar divulgado pelo Inep (2019).

O autor ainda diz, levando em conta que a Rede Estadual de Educação de São Paulo, a maior do País, cerca de 3,8 milhões de estudantes e cerca de 200 mil educadores e educadoras tiveram que rapidamente se adaptar, não somente a um novo estilo de vida frente à necessidade do afastamento social, mas também a ensinar (e aprender) dentro de um novo modelo de educação mediada por tecnologia. Para garantir a oferta de aulas e atividades e, ao mesmo tempo, oferecer em tempo real formação aos seus educadores, a Secretaria de Educação do Estado de São Paulo 
criou o Centro de Mídias da Educação de São Paulo, em funcionamento até esse momento.

Por esses motivos, o MEC lançou a portaria 544 de 2020, e, estendeu as aulas a distância até o final do ano e aprovou também a utilização de recursos educacionais digitais e tecnologias de informação e comunicação digitais, para dar continuidade no processo de ensino.

Nesse contexto, a centralidade deste artigo, opta por refletir nessas questões com base teórica em aportes bibliográficos de autores que estudam sobre o tema. Nesse sentido, corroborar com os professores para entender melhor na maneira de (re)inventar em suas práticas pedagógicas para elaborar as atividades, e se adequar no processo quanto às intervenções por meio do viés digital.

Diante dessa realidade vivenciada pelo professor, buscar-se-á compreender e refletir com este artigo, quais são as práticas pedagógicas essenciais que o professor necessita frente às necessidades na área da educação. Como ponto norteador da pesquisa, surgiu as seguintes questões: quais as práticas essenciais para que o professor consiga cumprir sua missão de ensinar e aprender em tempos pandêmicos? Como o professor pode elaborar essas práticas por meio de aulas remotas?

Para tentar responder e refletir nessas indagações, esse trabalho apropriar-se-á do pensamento de autores tais como: Nóvoa (2009), em "Para uma formação de professores construída dentro da profissão;" Nóvoa (2017), em "Firmar a posição como professor, afirmar a profissão docente;" Freire (2009), em Educação como prática da liberdade"; Nóvoa (2020), em "A pandemia de Covid-ı9 e o futuro da Educação"; Pérez (2021), em "Digitalización acelerada: lo que la pandemia le enseñó a la educación."entre outros.

Pautamos estas reflexões para discutir situações decorridas face à pandemia que trouxe a necessidade de adequação, e a obrigatoriedade de uma intervenção docente imediata nas práticas pedagógicas para continuar o processo de ensino e aprendizagem.

\section{I - METODOLOGIA}


Para a tessitura deste artigo, que o classificamos como uma pesquisa bibliográfica, que, segundo Gil (2017), é um tipo de pesquisa que se fundamenta com base em material já publicado em livros, artigos científicos, teses e dissertações, dentre outros.

O objetivo é analisar e refletir nas experiências vivenciadas no contexto do ensino remoto, que estão sendo realizadas por meio de atividades não presenciais para o desenvolvimento do efetivo trabalho docente em tempos de pandemia. Por meio desse trabalho investigativo, colocamo-nos na posição de professor pesquisador, como declara Silva (2014, p. 67), “[...] que, estando totalmente envolvido em sua prática - e justamente por estar envolvido - levanta constantes questionamentos acerca de suas ações, a fim de encontrar caminhos para o melhor desempenho de suas atividades e de seus pares, e assim, contribuir para a melhoria da educação”.

É importante salientar que, um trabalho de pesquisa quando é realizado pelo próprio professor, promove a ação em reflexão para repensar a própria prática pedagógica. Para enfatizar isso, Bortoni-Ricardo (2008), confirma que:

O docente que consegue associar o trabalho de pesquisa a seu fazer pedagógico, tornando-se um professor pesquisador de sua própria prática ou das práticas pedagógicas com as quais convive, estará no caminho de aperfeiçoar-se profissionalmente, desenvolvendo uma melhor compreensão de suas ações como mediador de conhecimentos e de seu processo interacional com os educandos. (BORTONI-RICARDO, 2008, p i9).

Para a elaboração deste trabalho, foi realizado um levantamento de dados coletados, a partir de outras pesquisas ${ }^{2}$ que tratam sobre o enfrentamento da emergência de saúde pública, em razão da pandemia Covid-ı9. Além de, vários autores que abordam o assunto em questão, notas técnicas, artigos científicos, reportagens sobre o tema, bem como, dados obtidos nos planos de aula e relatórios elaborados pelos professores que estão desenvolvendo atividades em tempos pandêmicos.

\section{2 - ENSINO REMOTO EM TEMPOS PANDÊMICOS}

\footnotetext{
${ }^{2}$ Grupo de Estudo GESTRADO/UFMG, (2020).
} 
Desde o março de 2020, logo que o vírus da Covid-ı́ foi descoberto, e com isso, houve várias vidas perdidas. O Ministério da Educação aprovou o decreto no 343, autorizando a substituição das aulas presenciais em aulas remotas (por meios digitais), enquanto a pandemia perdurar, fato que ocorre até o presente momento.

As escolas e universidades foram fechadas e o ensino remoto passou a fazer parte na rotina dos professores e alunos que os obrigaram a reformular suas próprias práticas da maneira que pudessem, porque a maioria das pessoas não estava preparada para esse desafio eminente.

Por isso, foi necessário que os professores (re)inventassem estratégias e meios para dar continuidade no processo de ensino e aprendizagem. Diante ao grande desafio da educação remota de emergência, alguns professores sentiram o peso da jornada de trabalho prolongada e seus reflexos na saúde mental, outros trabalham em redes que optaram por não realizar atividades à distância. Outros professores desenvolvem aplicativos para usar com os alunos e entrar em contato com grande parte da turma, desse modo, optando por trabalhar offline com materiais impressos com o apoio dos pais ou de instituições locais.

Em razão da necessidade da adequação aos novos e imediatos métodos para o ensino, as escolas e as universidades não tiveram outra saída, e optaram imediatamente pelo ensino à distância. Um dos setores mais afetado foi a educação infantil. Nesse ciclo estudantil, os professores tiveram e ainda têm que fazer muitos trabalhos para chamar a atenção das crianças, tais como: gravar vídeos aulas interessantes, contação de histórias, e outras atividades do gênero. Uma tarefa difícil!

Em tempos de pandemia, parece que o trabalho do professor se tornou mais complexo que exige mais conhecimento e esforço para fazer as atividades interessantes para os alunos aprenderem e com segurança.

De acordo com Arruda (2020):

A escola é um dos espaços sociais em que há maior intercâmbio e maior mobilidade de sujeitos de diferentes faixas etárias. Como tal, representa uma sala com maior probabilidade de contaminação em massa - indicando que será uma das últimas salas a reabrir em países que controlaram 
minimamente a taxa de contaminação do novo coronavírus. (ARRUDA, 2020, p. 263).

Nesse aspecto, a escola obedecendo as regras e cuidados para evitar o contágio entre alunos, professores e outros funcionários que fazem parte da instituição, optou pelo ensino remoto. Este tipo de ensino que está fazendo parte da maioria das escolas, vale salientar que é diferente do ensino à distância.

Para esclarecer melhor, o dicionário da língua portuguesa define que, o controle remoto significa: muito longe no tempo ou no espaço; que você pode adicionar ou conectar remotamente. (BECHARA, 20II, p. IOoI). Há evidência nessa definição que, esse tipo de ensino se dá por meio das tecnologias de comunicação e informação.

Não se deve confundir ensino remoto com a educação à distância. Elas não são a mesma modalidade para ensinar. A educação a distância pode ir além dos sistemas online, ou seja, é mais extensa e planejada, e envolve múltiplos recursos como vídeos, materiais impressos, e-books, textos em pdf entre outros. Já o ensino remoto se dá em tempo real de formas síncronas e assíncronas.

Em conformidade a essa modalidade de ensino, Pérez (202I), ressalva que a educação com a pandemia, sofreu uma abrupta mudança da noite para o dia, mas, que trouxe alguns benefícios como o engajamento dos professores para ampliar as suas práticas e a flexibilização de aprendizagem de forma autônoma. Ela diz:

De la noche a la mañana se pasó de una educación presencial - en la que todas las personas aprenden al mismo tiempo y en el mismo lugar- a una educación en la cual el aprendizaje puede darse en cualquier momento y en cualquier lugar. Se modificó el rol del profesorado, las personas encargadas de familia y del estudiantado que ahora tiene el reto de aprender de forma más autónoma. Con el apoyo de la tecnología, y buena formación, esto potencialmente puede implicar una educación mucho más flexible y personalizada. (PÉREZ, 202I, p.oI).

Desse modo, os professores tiveram que usar, como forma de amenizar o impacto na aprendizagem causado pela pandemia, ferramentas da internet para redesenhar suas atividades de ensino. Foi necessário (re)inventar as práticas pedagógicas para se adequar ao ensino remoto. Os professores precisaram lidar com ambientes até então desconhecidos e necessitando de ajuda para desenvolver suas 
habilidades por meios digitais. Com isso, levou a uma demanda de habilidades e competências exigidas ao professor para a reformulação do plano pedagógico e o uso de ferramentas tecnológicas para prosseguir no processo de ensino e aprendizagem.

Para Nóvoa (2020), a grande resposta ao impacto à pandemia, não veio de nenhum órgão público e nem do governo, mas, dos professores, que para dar continuidade ao ensino, precisaram ser capazes de manter o contato com os seus alunos e familiares.

Ele diz que:

[...] as melhores respostas à pandemia não vieram dos governos ou dos ministérios da educação, mas antes de professores que, trabalhando em conjunto, foram capazes de manter o vínculo com os seus alunos para os apoiar nas aprendizagens. Em muitos casos, as famílias compreenderam melhor a dificuldade e a complexidade do trabalho dos professores. Isso pode trazer uma valorização do trabalho docente e criar as condições para um maior reconhecimento social da profissão. (NÓVOA, 2020, p.02).

Para esse autor, as práticas colaborativas de professores foram decisivas para as melhores respostas nesse tempo pandêmico. Embora, às vezes injustamente acusados de imobilismo, conseguiram dar respostas criativas e plenas de significado pedagógico. Isso, traz uma reflexão importante para se admitir que nada pode substituir o professor, ele é a peça significativa para a engrenagem do processo de ensino e aprendizagem. E, completa dizendo que, a chave de qualquer processo educativo está sempre na relação humana entre um aluno e um professor.

\section{3 - AÇÃO DOCENTE NA CRISE E ISOLAMENTO SOCIAL}

O professor, depois da covid-19, assim como qualquer um de nós (inclusive os alunos), será um profissional mais preocupado com o outro, que valoriza a ação colaborativa e as relações interpessoais. A principal transformação que a crise nos trará está ligada ao envolvimento, engajamento e determinação para fazer e ser diferente nas ações para o ensino e aprendizagem.

É, notório que, a crise face à pandemia na área educacional tem sido desafiadora em todos os níveis de ensino, da educação básica ao ensino superior, uma 
vez que adaptação à modalidade remota e as desigualdades de acesso às tecnologias agravam o cenário de incertezas em que toda a comunidade escolar está inserida.

Sem as aulas presenciais, os educadores têm se desdobrado para dar conta de todos (ou quase todos) os alunos, ao mesmo tempo em que aprendem a lecionar em um contexto completamente diferente de um ano atrás. Embora, diante dos avanços tecnológicos e de inteligência artificial que observamos nos últimos anos, a pandemia reforçou o papel docente na aprendizagem e, consequentemente, na sociedade.

Para Freire (2003, p. 47) “[...] ensinar não é transferir conhecimento, mas criar as possibilidades para sua própria produção ou a sua construção". Este novo cenário que vivenciamos nos fez repensar a maneira com que o professor se relaciona com o estudante e os métodos utilizados para ensinar e aprender. Não há nada mais necessário no nosso novo modelo de ensinar

De acordo com Nóvoa (1995), pensar a profissão docente incorpora três dimensões indissociáveis: a pessoal, a profissional e a organizacional, o que fica ainda mais evidente no período da pandemia do que trazer este aluno para a possibilidade de criar a ajudar a construir o conhecimento.

Apesar de vivermos a era digital, com a explosão de mídias e com a globalização, vale ressaltar que nem todos têm acesso à internet. Mas, ter acesso à rede não significa dizer que há inclusão digital. De acordo com Pereira (2017, p. I5), "é preciso ir muito além do aprender a digitar em um computador.", haja vista que "precisamos dominar a tecnologia para que, além de buscarmos a informação, sejamos capazes de extrair conhecimento (PEREIRA, 2017, p. 17). Portanto, mesmo os professores tendo acesso aos equipamentos tecnológicos, não implica dizer que são letrados digitais, ou seja, que possuem habilidades para usar as ferramentas digitais disponíveis de forma proveitosa nas aulas online.

Diante disso, deve-se admitir, que houve uma sobrecarga de trabalho, pois, além de toda a preparação da aula, alguns professores tiveram que recorrer, na prática, ao aperfeiçoamento dos letramentos digitais, o que trouxe também uma sobrecarga emocional. Ainda que do outro lado da tela, está um aluno, centro da ação 
docente, que, embora, seja nativo da era digital, pode não possuir experiências com tais ferramentas tecnológicas para os objetivos propostos, sendo, então, necessário um desenvolvimento ou aperfeiçoamento da condição de letramento digital desses alunos exigidos por esse tipo de prática escolar atual.

Segundo uma pesquisa realizada pelo grupo de estudos GESTRADO/UFMG, (2020) ${ }^{3}$, sob a coordenação da Professora Dra. Dalila Andrade Oliveira, sobre o trabalho docente em tempos de pandemia, revela dados interessantes. Nesse trabalho, o público-alvo contempla os(as) professores(as) da Educação Básica das redes públicas estaduais e municipais. Conforme dados do Censo Escolar da Educação Básica de 2019, esse universo abrange cerca de 1,7 milhões de profissionais.

A coleta de dados ocorreu por meio de questionário online autoaplicado, disponibilizado na plataforma Google Forms. Os dados foram coletados no período de 8 a 30 de junho de 2020. Foram entrevistados 15.654 professores(as) das redes públicas da Educação Básica. A pesquisa contou com a parceria da Confederação Nacional dos Trabalhadores em Educação (CNTE), na mobilização dos respondentes e na divulgação dos resultados.

$\mathrm{Na}$ categoria perfil dos participantes, as mulheres representam $78 \%$ dos respondentes, sendo que metade dos professores participantes da pesquisa é constituída por mulheres com idade entre 30 e 49 anos. Ver na tabela.

Figura or - Tabela Perfil dos Participantes da Pesquisa.

\begin{tabular}{|l|l|l|l|}
\hline Faixa etária & Masculino & Feminino & Total \\
\hline Até 29 anos & $5,5 \%$ & $2,3 \%$ & $7,8 \%$ \\
\hline De 30 a 39 anos & $20,6 \%$ & $6,6 \%$ & $27,3 \%$ \\
\hline De 40 a 49 anos & $30,2 \%$ & $7,0 \%$ & $37,2 \%$ \\
\hline De 50 a 59banos & $19,0 \%$ & $4,7 \%$ & $23,7 \%$ \\
\hline
\end{tabular}

\footnotetext{
${ }^{3}$ Grupo de estudo da Universidade Federal de Minas Gerais (GESTRADO/UFMG, 2020). Esse grupo de estudo foi mencionado nesse artigo, para ilustrar as percepções teóricas da pesquisa porque se trata de uma fonte segura de informação. E, também, por se enquadrar numa possível reflexão para tentar responder ao problema de pesquisa levantado neste artigo.
} 


\begin{tabular}{|l|l|l|l|}
\hline 6o anos ou mais & $3,0 \%$ & I,O\% & $4,0 \%$ \\
\hline Total & $78,3 \%$ & $21,7 \%$ & $100,0 \%$ \\
\hline
\end{tabular}

Fonte: Adaptado do trabalho, GESTRADO/UFMG, (2020).

Essa pesquisa deixa claro que as mulheres predominam diante os cálculos percentuais de participantes do estudo. Já, quanto ao uso das tecnologias digitais em tempos pandêmicos, o isolamento social impôs novas rotinas de trabalho aos docentes.

O grande desafio para os professores em geral em tempos de crise pandêmica, foi na verdade, a oferta do ensino remoto. Essa modalidade de ensino, trouxe preocupação e necessidade de se reinventar as práticas pedagógicas com o uso das tecnologias para lidar no processo educativo. Ainda, de acordo com a pesquisa do GESTRADO/UFMG (2020), apenas, 28,9\% dos participantes do estudo afirmam possuir facilidade para o uso das tecnologias digitais de informação e comunicação.

A pesquisa observou também que, as dificuldades são ainda maiores quando os professores não receberam nenhuma formação para a utilização de ferramentas tecnológicas necessárias ao desenvolvimento das atividades remotas. Enfim, quanto aos desenvolvimentos de atividades escolares no sistema remoto, a pesquisa mostrou que, $86 \%$ passaram a realizar atividades de ensino remotas em função do rearranjo de trabalho provocado pela pandemia da Covid-ı.

Nisso, instaurou-se grande expectativa pelos professores por causa da situação inesperada de isolamento social e ter que assumir as atividades escolares sem um planejamento prévio, e uma preparação específica para esse momento. Por isso, é importante relatar como está sendo as novas configurações da atividade do professor da Educação Básica pública no país após o distanciamento social decorrente da pandemia da Covid-rg.

Diante esse quadro de distanciamento social, face à pandemia causada pela Covid-19, grande parte (84\%) dos(as) professores(as) não param suas ações pedagógicas, e continua a desenvolver atividades de trabalho de forma remota. 
Um gráfico elaborado pelo autor desse artigo, adaptado da pesquisa feita pelo grupo de estudo GESTRADO/UFMG (2020), vai ilustrar os dizeres do estudo.

\section{Figura 02 - Gráfico Representativo das Atividades Escolares na Pandemia.}

\section{Realização de atividades não presenciais}

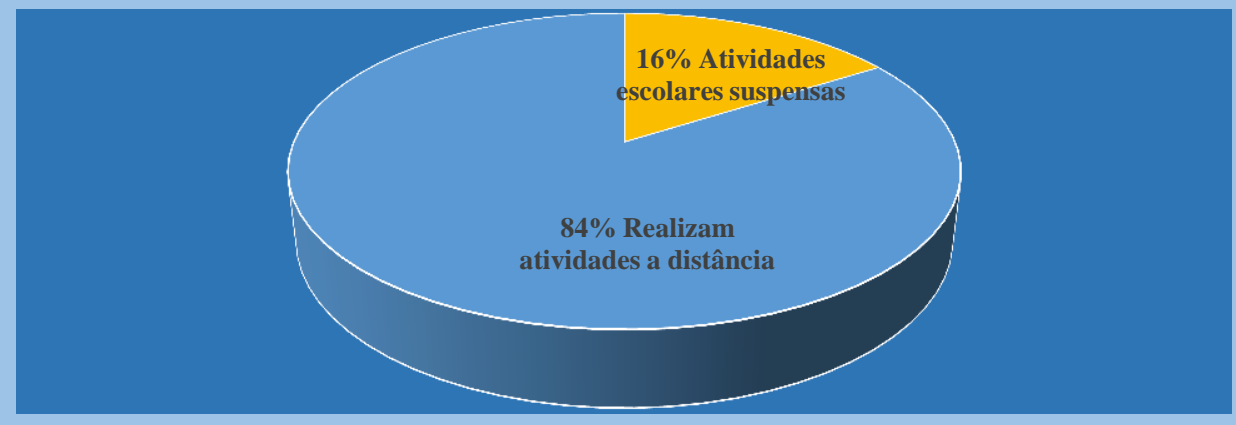

Fonte: Adaptado do Grupo de Estudo, GESTRADO/UFMG (2020).

Apesar da situação ser completamente nova e inesperada, ou seja, ninguém estava preparado para enfrentar os desafios que a pandemia nos impõe, os professores (re)inventaram as práticas pedagógicas da melhor forma possível para não parar com o processo de ensino.

Nesse aspecto, os professores foram convocados, na maioria dos casos, a realizarem seu trabalho de outra maneira, em outros contextos, inclusive virtual, adaptando suas atividades, desenvolvendo habilidades para lidar com novas ferramentas e metodologias para responder a essa situação inteiramente inusitada para a educação na atualidade.

Percebe-se que, a maioria desses profissionais não recebeu qualquer formação para o desenvolvimento das atividades escolares. Entretanto, nota-se que o compromisso dos professores(as) com seus alunos tem orientado a busca de meios para tornar a oferta educativa possível e contínua. Enfim, talvez, essa experiência possa significar um importante crescimento e amadurecimento profissional dos professores, mas ela também é geradora de tensões e angústias para esses profissionais. 


\section{4 - (RE)INVENTANDO ESTRATÉGIAS DE ENSINO NA PANDEMIA}

Com a chegada da pandemia, a recomendação dos órgãos de saúde pública foi o isolamento social. Com isso os estados e municípios fecharam suas escolas, suspenderam as aulas em razão da pandemia, comprometendo o ano letivo de muitos estudantes (BRASÍLIA,2020).

Para um ensino de qualidade, deve refletir diretamente no envolvimento do aluno com a aprendizagem. Mas, o grande desafio enfrentado pelos Núcleos de Educação e suas escolas foi preparar estratégias para o ensino dos alunos em tempos de pandemia, a fim de cumprir o calendário escolar, (re)inventando práticas com o uso das tecnologias digitais.

Em tempos de mudanças inesperadas no cenário escolar, por causa do isolamento social, foi necessário que os professores repensassem as práticas, e assim, cumprir o calendário letivo. Vale citar aqui o que ressalta Moran (2017, p.66), ele, destaca que nos processos de ensino é preciso "saber adaptar-nos a soluções inesperadas e criar novas soluções para novos problemas”.

Com a avassaladora evolução da tecnologia no Brasil e no mundo em diversos contextos sociais, o cenário escolar passou a adotar os recursos tecnológicos como estratégia pedagógica muito antes do momento pandêmico emergente. Assim, muitas barreiras foram rompidas entre o ensino físico e virtual, criando uma nova linguagem, a educação híbrida (BACICH e MORAN, 2018).

Desse modo, foram usadas como estratégias educacionais, as tecnologias de informação e comunicação como mediadoras entre professores e alunos. O conteúdo foi adaptado para o formato digital, em videoaulas e arquivos, preparados pelos próprios professores ou disponibilizados pelas redes de ensino.

É importante pensar em diversas estratégias para que os alunos se aprofundem num mesmo conteúdo. Há diversos caminhos possíveis para dialogar com os alunos os conteúdos, tais como: vídeos, blogs, facebook, whatsapp, sites, conversas online por chats etc. 
Por exemplo, $\mathrm{O}$ ensino pode ocorrer com o suporte de outros recursos didáticos que não seja apenas a explicação verbal e a escuta passiva. O professor pode dar outras vozes e várias cores a um conteúdo abstrato. Pode apagar as luzes e mergulhar a sala numa reflexão animada por desenhos e formas, num clima de expectativa, isso para chamar a atenção do aluno. Pode também, fotografar e filmar as aulas, depois editar um vídeo resgatando o percurso de uma disciplina. E, ainda, o professor pode começar uma aula com um vídeo, depois colocar as perguntas no telão, pode pedir tudo isso em silêncio, sem pronunciar palavra alguma. Pode solicitar que os alunos escrevam suas reflexões num computador e publiquem num blog ou jornal, e até mesmo no mural da turma ou escola.

Nesse contexto, de (re)inventar práticas pedagógicas do professor, em tempos tão obscuros nos chega em diálogo com o pensamento de Sayegh (1998) quando diz que:

[...] vive-se uma época de acomodação mental, em que se recebe informações prontas, métodos de estudo dirigido repetitivos, devido aos quais os espíritos amoldam-se na passividade de simples combinações de ideias prontas. Não se aprende a pensar por si mesmo, mas vive-se a superficialidade da soma de concepções adquiridas; eis já o início de preconceito a que a sociedade nos conduz. A verdadeira liberdade está no poder de criação. Não podemos nos preocupar apenas em resolver uma questão dada, pois buscar a solução é uma operação aplicada a termos estáticos. Descobrir? Sim, mas a descoberta consiste ainda em colocar aquilo que já existia virtual ou atualmente. Porém, inventar, criar é suscitar engendrando-se na realidade dinâmica do espírito. É criar a si mesmo, inserindo-se na articulação natural da realidade do espírito, somente assim encontraremos a liberdade, ou seja, este poder de decisão semidivino, de criação, de atualização do verdadeiro. (SAYEGH, 1998, p. 46-47).

Para se refletir que, (re)inventar a profissão docente em tempos adversos não é nada fácil, (re)inventar a nós mesmos em nossa maneira de viver em situação de distanciamento social, também não é fácil, mas sim, é possível e devemos tentar.

Embora, a concepção de (re)inventarmos enquanto professores e professoras não seja recente, ela já vem sendo pensada há tempos. Talvez receba outra 
nomenclatura, mas sua natureza de (re)invenção esteja latente. Isso, nos leva apensar o que diz Nóvoa (1999) e por Schön (1997), para que possamos ser professores reflexivos, ou seja, profissionais capazes de pensar, analisar e questionar a própria prática com a finalidade de agir e aprimorá-la construindo uma atuação autônoma, possibilitando, também aos alunos, a construção da autonomia, tão importante em tempos de crise em que a tomada de decisão possa ser real e legítima para uma aprendizagem significativa.

Isso, também, é o que nos recomenda Becker e Marques (2010), para que possamos ser professores-pesquisadores, cuja principal intencionalidade seja contextualizar o que ensinamos por meio de uma atividade investigadora e reflexiva da própria prática, levando em conta, tanto a própria condição quanto a do aluno em termos cognitivos, sociais, econômicos e tecnológicos no meio em que vive. Destarte, é preciso refletir na concepção de Freire (1997), que apesar da crise, talvez possamos nos engendrar na esperança, e desse modo, já agiremos nesse aspecto de (re)inventar práticas. Embora, não podemos descartar o desespero que às vezes se faz presente no dia a dia, trazendo doses de desesperanças, mas, acreditar que a esperança e o sonho como estratégias de luta para fazer o melhor nas atividades práticas.

Freire (2016), adverte sobre a esperança assim:

Pensar que a esperança sozinha transforma o mundo e atuar movido por tal ingenuidade é um modo excelente de tombar na desesperança, no pessimismo, no fatalismo. Mas, prescindir da esperança na luta para melhorar o mundo, como se a luta se pudesse reduzir a atos calculados apenas, à pura cientificidade, é frívola ilusão. [...] O que é essencial [...], é que ela, enquanto necessidade ontológica, precisa de ancorar-se na prática. Enquanto necessidade ontológica, a esperança precisa da prática para tornar-se concretude histórica. (FREIRE, 20I6, p. 15)

$\mathrm{Na}$ percepção desse autor, sem a esperança, não estaremos aptos nem mesmo iniciar a luta. Todavia, é possível que seja isso, empreender nossa iniciativa de escolha, assumir a responsabilidade por nossas ações, embasadas pela esperança de que em tudo há aprendizado. Há um adágio popular que diz: “a esperança é a última que morre". Mas, para nós professores que devemos ter essa esperança intrínseca, certamente ficaria assim: "a esperança é a última que não morre”. Talvez, seja esse 
um pressuposto para a reflexão do professor para o trabalho no ensino a distância em tempos de pandemia na atualidade.

\section{5- O ATO REFLEXIVO DA/NA PRÁTICA PEDAGÓGICA DO PROFESSOR: ALGUNS PRESSUPOSTOS EM TEMPOS DIFÍCEIS}

Ao longo da história da educação, o professor era visto como um detentor do saber, como um profissional único, que apenas deveria repassar conhecimentos aos seus alunos, sem preocupar-se em refletir $\mathrm{da} /$ na prática elaborada, nem com a contribuição desta para o avanço ou retrocesso da aprendizagem dos alunos.

Nessa perspectiva, é notório salientar que, concepções como estas vêm sendo cada vez mais descartadas e repensadas por estudiosos, pesquisadores e pelos próprios professores, que percebem ainda mais, as dificuldades que enfrentam em sala de aula bem como a probabilidade de melhoria dela. Destarte, por meio do ato reflexivo e do conhecimento voltado para a sua prática, que possibilitaria um novo olhar e despertaria novas perspectivas para a melhorar o seu trabalho como profissional, principalmente no cenário da educação em tempos de pandemia.

Para o nosso entendimento, o ato reflexivo propicia e valoriza a construção pessoal do conhecimento, viabilizando novas maneiras de apreender, de compreender, de atuar e de solucionar problemas, corroborando para que se adquira maior consciência e controle sobre o que se faz.

Em tempos obscuros e de pandemia, o ato reflexivo do professor se torna tão necessário para que possa desempenhar as ações pedagógicas com propósitos para um ensino eficaz, mediante situações adversas e adequar-se a possíveis possibilidades e estratégias (ensino remoto e o uso das TICs) disponíveis no momento.

Como afirma Schön (200o),

[...] é possível através da observação e da reflexão sobre nossas ações, fazermos uma descrição do saber tácito que está implícito nelas. Nossas descrições serão de diferentes tipos, dependendo de nossos propósitos e das linguagens disponíveis para essas descrições. Podemos fazer referência, por exemplo, às sequências de operações e procedimentos que executamos; aos 
indícios que observamos e às regras que seguimos; ou os valores, às estratégias e aos pressupostos que formam nossas "teorias da ação". (SCHÖN, 200o, p. 3I)

Dessa forma, imaginamos que, o ato reflexivo da/na prática do professor, é um pressuposto que pode provocar mudanças no perfil desse profissional da educação, que deve por meio da reflexão e do pensamento crítico, verificar a situação da prática como docente nas atividades em curso, tão necessário para esse tempo difícil de pandemia. Nesse ato, é possível identificar os pontos positivos ou negativos, e saber o que está sendo construído, verificando assim, sua legitimidade, sua validez enquanto ato que proporciona conhecimentos significativos para os alunos envolvidos no processo de ensino e aprendizagem.

E, por falar em reflexividade na prática pedagógica do professor, isso nos remete ao autor da expressão "pensamento reflexivo", Dewey (1979). Essa expressão originou-se na década de 1930, nas formulações, sobre a compreensão da realidade e a construção de significados a partir das experiências vividas. Para ele, a reflexão consiste na capacidade de distinguir:

[...] entre aquilo que tentamos fazer e o que sucede como consequência. [...] $\mathrm{Na}$ descoberta minuciosa das relações entre os nossos atos e o que acontece em consequência delas, surge o elemento intelectual que não se manifesta nas experiências de tentativa e erro. À medida que se manifesta esse elemento aumenta proporcionalmente o valor da experiência. Com isto, muda-se a qualidade desta, e a mudança é tão significativa que poderemos chamar reflexiva esta espécie de experiência, isto é, reflexiva por excelência. [...] Pensar é o esforço intencional para descobrir as relações específicas entre uma coisa que fazemos e a consequência que resulta, de modo a haver continuidade entre ambas. (DEWEY, 1979, p. 158).

Desse modo, seguindo esses parâmetros, deve-se acreditar que o professor a partir da reflexão, pode reconstruir a prática pedagógica e favorecer o desenvolvimento de uma aprendizagem significativa por parte dos alunos. Nesse sentido, conceber a ideia de que o conhecimento elaborado por meio da reflexão da prática do professor, pode levá-lo a melhorar seu trabalho a partir de pressupostos que viabilizem o trabalho de um conjunto de transformações fidedignas, que irão proporcionar uma melhor qualidade do/no seu ensino como ação reflexiva. 
Para refletir sobre a prática pedagógica do professor, podemos pensar no processo de ensino-aprendizagem, onde os alunos devem considerados como protagonista de toda a ação para aprender. Nesse aspecto, Paulo Freire (1997, p.14) fala que o professor, na sua prática docente, precisa instigar a capacidade crítica de seu aluno, pois para o autor “aprender criticamente é possível” para que assim esses alunos possam construir seus próprios conhecimentos, por meio da inquietação, questionamentos, curiosidades e indagações.

Nessa perspectiva reflexiva, surge a curiosidade como pressuposto tão necessário para o exercício crítico da profissão de ensinar e aprender. A curiosidade é, portanto, elemento importante para o desvelamento das coisas do mundo. Em conformidade a isso, Freire (1997) relata que:

A curiosidade como inquietação indagadora, como inclinação ao desvelamento de algo, como pergunta verbalizada ou não, como procura de esclarecimento, como sinal de atenção que sugere e alerta faz parte integrante do fenômeno vital. Não haveria criatividade sem a curiosidade que nos move e que nos põe pacientemente impacientes diante do mundo que não fizemos, acrescentando a ele algo que fazemos. (FREIRE,1997, p. 18).

Atentar para estes pressupostos de reflexão crítica, é refazer uma metodologia que já rotineiramente está estruturada, é repensar sua prática e, acima de tudo, transformar sua vivência em sala de aula dependendo das dificuldades apresentadas, o que irá exigir esforço, tempo, dedicação e fundamentação. Por tais motivos atender as necessidades exigidas por essa reflexão, não é tão fácil na realidade vivenciada por todos os professores nesses tempos difíceis, o que dificulta as transformações que em muitas salas de aulas são indispensáveis nesses momentos de (re)adequações causadas pelo vírus da Covid-ı.

E, por fim, é importante pensar em alguns movimentos que caracterizam a concepção de professor reflexivo. Para isso, com as contribuições de Schon (2000) e Perrenoud (2002), nos mostram sentidos da reflexão necessários ao profissional reflexivo; e conceituando cada um desses movimentos, tais como:

\section{Figura 03 - Quadro Demonstra Movimentos Necessários ao Professor Reflexivo}




\section{CARACTERIZANDO A CONCEPÇÃO DO PROFESSOR REFLEXIVO SEGUNDO SCHON (2000) E PERRENOUD (2002).}

A reflexão-na-ação: aproximação do professor com o problema.

A reflexão sobre-a ação: questiona a ação desenvolvida ou praticada.

A reflexão-sobre-a-reflexão-na-ação: investigador da prática e analisa além delas.

Fonte: Elaborado pelo autor deste artigo, (2021).

A reflexão-na-ação: essa é o tipo de reflexão que proporciona uma ampla aproximação do professor com o problema ou necessidade apresentada, ou seja: durante a ação vai permitir ao professor compreender criticamente o processo que naquele momento permeia o que está acontecendo no calor da ação.

[...] A reflexão-na-ação tem uma função crítica, questionando a estrutura de pressupostos do ato de conhecer-na-ação. Pensamos criticamente sobre o pensamento que nos levou a essa situação difícil ou essa oportunidade e podemos, neste processo, reestruturar as estratégias de ação, as compreensões dos fenômenos ou as formas de conceber os problemas. (SHÖN, 2000, p. 33).

Nessa perspectiva, a reflexão na ação, ocorre no ato de conhecer na ação. $\mathrm{O}$ problema ou necessidade se apresenta e neste momento o professor refletirá em torno do que seria necessário fazer para solucioná-lo. Assim, o professor acaba por dialogar com a situação que está ocorrendo, buscando solucionar os problemas que surgiram.

A reflexão sobre-a ação, vai proporcionar um sentido retrospectivo, uma vez que provoca no professor, uma análise da ação desenvolvida, procurando despertar nele uma melhor compreensão a fim de que caso a ação se repita, o professor já tenha consciência do que seria necessário fazer, ou como agir. Esse movimento reflexivo vai provocar no professor questionamentos que permeiam a ação que ele desenvolveu, onde ele busca conhecer os resultados que sua ação provocou, comparando-os com os resultados esperados, compreendendo assim os significados que sua ação tem e os significados que ela deveria ter.

E, por fim, a caracterização do professor reflexivo na reflexão-sobre-areflexão-na-ação, na concepção desses autores, faz com que o professor seja um verdadeiro investigador de sua prática, analisando além das ações desenvolvidas, os 
saberes que a norteiam, a teoria na qual as ações foram desenvolvidas, agindo criticamente em torno de sua prática: o porquê de refletir, o que o levou a refletir sobre a ação, por isso uma reflexão-sobre-a-reflexão-na-ação.

Desse modo, [...] visando chegar a uma verdadeira prática reflexiva, essa postura deve se tornar quase permanente, inserir-se em uma relação analítica com a ação [...] (PERRENOUD, 2002, p. 13). Nesse sentido, o autor adverte que a reflexão na/da concepção do professor sobre as práticas, deve ser permanente e contínua, que permita ao professor por ela envolvido, compreender as ações por ele desenvolvidas, analisá-las e, caso seja necessário, reconstruí-las.

Vimos nesse artigo que, o processo que envolve a prática pedagógica do professor reflexivo é complexo e envolve uma série de ações permeadas e subsidiadas pela reflexão. Mas, para transformar as ações do professor não reflexivo em ações crítico-reflexivas, requer reposicionamentos, reconstrução de concepções e, acima de tudo, necessita primeiramente que o professor assuma uma postura crítica frente a sua prática.

Portanto, para tornar-se um professor reflexivo, irá depender fundamentalmente da visão do próprio profissional frente as necessidades de seu trabalho, as necessidades de se pesquisar e reconstruir sua prática pedagógica, e, sobretudo as necessidades de seus alunos o que poderá levar a uma grande transformação e o professor deve estar preparado para tal ato, bem como está sendo feito por todos os professores que se (re)inventaram em tempos de pandemia.

\section{CONSIDERAÇÕES FINAIS}

O grande impacto causado pela pandemia do Coronavírus foi geral em todas as áreas da sociedade. $\mathrm{Na}$ esfera educacional, atingiu principalmente atores pedagógicos envolvidos nessa prática desde o início da pandemia. Segundo algumas pesquisas $^{4}$, famílias, alunos e responsáveis, principalmente os professores que são os participantes desse estudo, equipes pedagógicas, diretores e secretarias, tiveram que

\footnotetext{
${ }^{4}$ Ver a citação na pesquisa do grupo de estudo GESTRADO/UFMG (2020).
} 
fazer (re)adaptações na rotina e na metodologia para continuar o processo de ensino e aprendizagem.

Partindo do pressuposto de que o ato de ensinar e aprender é constituído de relações humanas, não podemos deixar de refletir, que os professores também são seres humanos e têm que lidar com a necessidade de adaptar-se aos recursos digitais, para preparar atividades que possam motivar os alunos e, ao mesmo tempo, que também precisam exercer outros deveres no âmbito familiar por conto do trabalho Home Office.

Nesse sentido, é importante aclarar que estamos vivendo em tempos pandêmicos, e que isso, trouxe um grande impacto e mudanças no cenário da/na educação. Diante dessa realidade, e para não perder o ano letivo, visto que as escolas brasileiras fecharam as portas por decreto das autoridades competentes, as secretarias municipais e estaduais de educação optaram pelo ensino remoto emergencial.

Inicialmente, essa modalidade de ensino, não tinha a pretensão de substituir as aulas presenciais, e sim, apenas atuar de forma temporária, utilizando-se ou não das tecnologias digitais como ferramentas possíveis nas atividades e comunicação entre escola, família, professores e alunos, e assim, colocar em prática atividades pedagógicas propostas no currículo para continuar o ano letivo.

Desse modo, este artigo procurou analisar as práticas pedagógicas de professores em tempos de pandemia, tentando responder as seguintes questões que trouxemos para o roteiro de nosso estudo: quais as práticas essenciais para que o professor consiga cumprir sua missão de ensinar e aprender em tempos pandêmicos? Como o professor pode elaborar essas práticas por meio de aulas remotas? Destarte, com base nessas indagações e centrado em três aspectos importantes para o desenvolvimento das práticas pedagógicas tais como: o uso das tecnologias digitais nos processos de ensino-aprendizagem, a ação docente e o ato reflexivo sobre as estratégias de ensino do professor da/na própria prática, sendo estes os protagonistas envolvidos na área da educação. 
Como resposta e resultado dessa pesquisa, vimos que, diante desse cenário pandêmico, e concluímos que, a educação passou e passa por uma revolução em seus métodos de ensinar. Por isso, diante dos hercúleos desafios enfrentados por todos os professores, alunos e os que fazem parte do âmbito escolar, ficam algumas experiências boas e outras nem tanto, mas todas servirão como aprendizado, talvez para valorizar o que tínhamos, seja para ampliar o olhar em um sentido diferente e mais completo daqui para a frente. Vale citar que a necessidade e a superação foram os regentes no processo de ensino e aprendizagem. Destarte, a necessidade de continuar e a superação por parte dos professores e alunos, mesmo com dificuldades, mas todos engajados no desafio do medo, da angústia, da tristeza e da aflição diante da possibilidade de contrair o COVID -I9, mas, nunca desistiram de exercer as atividades pedagógicas.

Espera-se que o presente trabalho possa promover maiores esclarecimentos acerca das práticas pedagógicas, bem como possa servir de base para estudos posteriores que busquem compreender e refletir no impacto que o fenômeno Coronavírus causou no cenário educacional. Desse modo, deixou claro a importância da relação professor/aluno para a aprendizagem, e que daqui para a frente, deverá ocorrer (já estar ocorrendo) uma significativa mudança nas práticas escolares desenvolvidas, pois esta foi e será o maior desafio para todos os atores envolvidos no âmbito educacional, quer seja na pandemia ou fora dela, e assim, a escola nunca mais será a mesma de antes da COVID-ig.

\section{REFERÊNCIAS BIBLIOGRÁFICAS}

ARRUDA, Eucidio Pimenta. Educação remota emergencial: elementos para políticas públicas na educação brasileira em tempos de Covid-19. Em Rede - Revista de Educação a Distância, v. 7, n. I. 2002. Disponível em: https://www.aunirede.org.br/revista /index.php/emrede/article/view/621. Acesso em: I6 abr. 2021.

BECHARA, Evanildo. Dicionário da Língua Portuguesa. I I $^{\mathrm{a}}$ ed. Rio de Janeiro: Editora Nova Fronteira, 20II.

BECKER, F.; MARQUES, T.B.I. (org.) Ser professor é ser pesquisador. Porto Alegre: Mediação, 2010. 
BORTONI-RICARDO, S. M. O professor pesquisador: introdução à pesquisa qualitativa. São Paulo: Parábola Editorial, 2008.

BRASÍLIA. Senado Federal. Projetos do Senado Minimizam prejuízos na educação por causa da pandemia. Brasília; 2020. Disponível em: wwwi2.senado.leg.br/noticias/materias/202 o/04/o8/projetos-do-senadominimizam-prejuizos-na-educacao-por-causa-da-pandemia. Acesso em 23 abr. 2021.

DEWEY J. Democracia e educação. São Paulo: Companhia Editora Nacional; 1979.

DIÁRIO OFICIAL DA UNIÃO. A substituição das aulas presenciais por aulas em meios digitais enquanto durar a situação de pandemia do Novo Coronavírus COVID-i9. PORTARIA № 343, DE 17 DE MARÇO DE 2020. Acesso em 25 abr. 2021.

FREIRE, Paulo. Pedagogia da Autonomia: saberes necessários à prática docente. 3. ed. São Paulo: Paz e Terra, 1997.

FREIRE, Paulo. Pedagogia da autonomia: saberes necessários à prática educativa. São Paulo: Paz e Terra, 2003.

FREIRE, Paulo. Pedagogia da esperança: um reencontro com a pedagogia do oprimido. São Paulo/Rio de Janeiro: Editora Paz e Terra, 2016.

FREIRE, Paulo. Pedagogia da Autonomia: saberes necessários à prática docente. 3. ed. São Paulo: Paz e Terra, 1997. FREIRE, P. Pedagogia da esperança: um reencontro com a pedagogia do oprimido. São Paulo/Rio de Janeiro: Editora Paz e Terra, 2016.

GIL, A. C. Como elaborar projetos de pesquisa. 5 ed. São Paulo: Atlas, 2017.

GRANDISOLI, Edson. Educação e pandemia: desafios e perspectivas. Jornal da USP. Instituto de Energia e Ambiente (IEE) da USP, em I2/o8/2020.

MORAN, José. Metodologias ativas para uma aprendizagem mais profunda. In: BACICH, Lilian., MORAN, José. (Org). Metodologias ativas para uma educação inovadora: uma abordagem teórico-prática. [recurso eletrônico]. - Porto Alegre: Penso, 2018.

MORAN, José. Como Transformar nossas escolas. Novas formas de ensinar a alunos sempre conectados. Publicado no livro Educação 3.0: Novas perspectivas para o Ensino. CARVAlHO, M. (Org). Porto Alegre, Sinepe/RS/Unisinos, 2017. Disponível em: http://www2.eca.usp.br/moran/wpcontent/uploads/2017/o8/transformar_escolas.pdf. Acesso em 24 abr. 202I.

NÓVOA, Antonio. Formação de professores e profissão docente. In: NÓVOA, A. Os professores e sua formação. 2. ed. Lisboa: Dom Quixote, 1995· p.13-33.

NÓVOA, Antonio. Os professores na virada do milênio: do excesso dos discursos à pobreza das práticas. Educação e Pesquisa, São Paulo, v. 25, n. I, p. II-20, I999. 
NÓVOA, Antonio. A pandemia de Covid-ı́ e o futuro da Educação. Entrevista à Revista Com Censo (RCC), \#22 • volume $7 \cdot$ número 3, agosto de 2020. O periódico é vinculado à Secretaria de Estado de Educação do Distrito Federal, Brasil.

NÓVOA, Antonio. Firmar a posição como professor, afirmar a profissão docente. Caderno de Pesquisa, Fundação Carlos Chagas. http://publicacoes.fcc.org.br/index.php/cp/issue/view/329. Acesso em 25 abr. 202I.

OLIVEIRA. Dalila Andrade. Trabalho Docente em Tempos de Pandemia. Grupo de Estudos sobre Política Educacional e Trabalho Docente (GESTRADO/UFMG). Acesso em: 23 abr. 2020.

PERRENOUD, Philippe. A prática reflexiva no ofício do professor: Profissionalização e Razão Pedagógica. Porto Alegre: Artmed, 2002.

PÉREZ, Estíbaliz. Digitalización acelerada: lo que la pandemia le enseñó a la educación".

Acesso em: 17 abr.2021. https://blogs.iadb.org/educacion/es/digitalizacion-aceleradalo-que-la-pandemia-le-enseno-a-la-educacion/. Doctora en Educación de la Universidad Autónoma de Madrid.

PEREIRA, J. T. Educação e sociedade da informação. In.: COSCARELLI, C. V.; RIBEIRO, A. E. (org). Letramento digital: aspectos sociais e possibilidades pedagógicas. 3. ed. Belo Horizonte: Ceale/Editora autêntica, 2017. p. 13-24.

SAYEGH, A. Bergson: o método intuitivo, uma abordagem positiva do Espírito. São Paulo: Humanitas / FFLCH/USP, 1998.

SILVA, A. J. N. A Ludicidade no Laboratório: considerações sobre a formação do futuro professor de matemática. Curitiba, PR: Editora CRV, 2014.

SCHÖN, Donald. A. Formar professores como profissionais reflexivos. In: NÓVOA, A. (org.). Os professores e sua formação. Lisboa: Publicações Dom Quixote, 1997. p. 93-II4.

SCHÖN, Donald, A. Educando o profissional reflexivo: um novo design para o ensino e a aprendizagem. Porto Alegre: Artmed, 2000. 